\title{
4-Hexylresorcinol inhibits osteoclastogenesis by suppressing the NF-кB signaling pathway and reverses bone loss in ovariectomized mice
}

\author{
WENKAI YI, TAO LIU, XINFENG GAO, YONGHUA XIE and MING LIU \\ Department of Spine Surgery, Pu Ai Hospital of Wuhan City, Tongji Medical College, \\ Huazhong University of Science and Technology, Wuhan, Hubei 430000, P.R. China
}

Received August 4, 2020; Accepted January 18, 2021

DOI: $10.3892 /$ etm.2021.9785

\begin{abstract}
Hexylresorcinol (4HR) is a small organic compound that is widely used as an antiseptic and antioxidant. In the present study, its role in osteoclastogenesis was investigated. Bone marrow-derived macrophages from mice were used to examine the role of 4HR in osteogenesis. An ovariectomy (OVX) mouse model was constructed to examine the effect of 4HR in vivo, followed by hematoxylin and eosin and tartrate resistant acid phosphatase staining. In the present study, 4HR effectively suppressed receptor activator of $\mathrm{NF}-\kappa \mathrm{B}$ ligand-induced osteoclastogenesis in a dose-dependent manner. 4HR was also found to significantly suppress the expression of osteoclast (OC)-specific markers, including tartrate-resistant acid phosphatase, cathepsin $\mathrm{K}$, nuclear factor of activated T-cell cytoplasmic 1 and c-Fos in the presence of RANKL in BMMs. Furthermore, 4HR inhibited osteoclastogenesis by inhibiting the activation of the $\mathrm{NF}-\kappa \mathrm{B}$ signaling pathway in BMMs. Consistent with the in vitro results, $4 \mathrm{HR}$ effectively ameliorated OVX-induced bone loss and markedly reduced OC number in the proximal tibia in vivo. In conclusion, the present results suggested
\end{abstract}

Correspondence to: Dr Ming Liu, Department of Spine Surgery, Pu Ai Hospital of Wuhan City, Tongji Medical College, Huazhong University of Science and Technology, 473 Hanzheng Street, Wuhan, Hubei 430000, P.R. China

E-mail: Ming_Liu12@hotmail.com

Abbreviations: 4HR, 4-Hexylresorcinol; OC, osteoclast; OB, osteoblast; BMM, bone marrow-derived macrophages; M-CSF, macrophage colony stimulating factor; CCK-8, Cell counting kit-8; RANKL, receptor activator of NF- $\mathrm{B}$ ligand; TRAP, tartrate-resistant acid phosphatase; NFATc1, nuclear factor of activated T-cells cytoplasmic 1; OVX, ovariectomy; BV/TV, bone volume/total volume; Tb.N, trabecular number; Tb.Th, trabecular thickness; Tb.Sp, trabecular separation; P1NP, C-telopeptide of type I collagen; CTX1, C-terminal telopeptide of type1 collagen

Key words: 4-Hexylresorcinol, osteoclast, osteoclastogenesis, ovariectomy that 4HR inhibited osteoclastogenesis in vitro and rescued bone loss in vivo, suggesting that $4 \mathrm{HR}$ may serve as a novel therapeutic agent for osteoporosis treatment.

\section{Introduction}

Osteoporosis is one of the most common diseases among the elderly and post-menopausal women (1). It is characterized by low bone mineral density and a high risk of fractures (2), which are frequently associated with high mortality and significant morbidity rates, in addition to high risks of pain and disability (3). It was reported osteoporotic fracture is high and lies within the range of $40-50 \%$ in women and $13-22 \%$ in men aged $>50$ years (4). Therefore, investigating the cause of this disease is of importance. As previous studies have shown, osteoporosisis a disease caused by the imbalance between the activities of osteoblasts (OBs) and osteoclasts (OCs) $(5,6)$, specifically the reduced number of OBs and increased number of OCs (7). OCs are giant multinucleated bone-resorbing cells that are differentiated from mononuclear macrophages (8). Throughout an individual's life, bones continuous undergo remodeling through bone matrix formation and mineralization (anabolic process) by OBs (9) and mineralized bone matrix degradation (catabolic process) by OCs (10). During osteoclastogenesis, macrophage colony-stimulating factor (M-CSF) and receptor activator of $N F-\kappa B$ ligand (RANKL) are essential for OC differentiation, which also support the function and survival of mature osteoclasts $(11,12)$. Disruptionsin the interaction between RANKL and RANK using the human monoclonal antibody denosumab was found to prevent OC formation, activity and survival (13-15). However, novel therapeutic strategies for the intervention of osteoclastogenesis have not been extensively studied. Potential anti resorptive drugs include estrogens (with or without progesterone), bisphosphonates (alendronate, risedronate, ibandronate and zoledronic acid), the estrogen agonist/antagonis traloxifene and salmon calcitonin (16). However, thus far teriparatide and recombinant human parathyroid hormone are the only approved anabolic agents (17), Denosumab, a human monoclonal antibody for RANKL, has been found to inhibit osteoclastogenesis and was approved for treating osteoporosis (18). 
4-hexylresorcinol (4HR) is a small organic compound that has been previously used as an additive antiseptic and antioxidant (19). 4HR was first used as an anti-parasitic and antiseptic agent (20). Due to the development of superior antiparasitic agents, the use of $4 \mathrm{HR}$ as an anti-parasitic agent has now diminished (21). However, 4HR remains to be used widely as an anti-microbial in cosmetics and antiseptics (22). 4HR was shown to accelerate orthodontic tooth movement and increase the expression levels of bone turnover markers, including osteocalcin, osteotonpin and RUNX2, in ovariectomized rats, indicating a role for $4 \mathrm{HR}$ in bone remodeling (23). However, the role of $4 \mathrm{HR}$ in osteoclastogenesis remain to be fully elucidated.

Since it was reported that $4 \mathrm{HR}$ can inhibit the $\mathrm{NF}-\kappa \mathrm{B}$ pathway in human nasopharyngeal carcinoma cells (21), it was therefore hypothesized that $4 \mathrm{HR}$ could inhibit osteoclastogenesis by suppressing the $\mathrm{NF}-\kappa \mathrm{B}$ signaling pathway. In the present study, the role of $4 \mathrm{HR}$ in osteoclastogenesis in both BMM cells and in a OVX mouse model was examined. Results from the present study may provide a novel therapeutic strategy for the treatment of osteoporosis.

\section{Materials and methods}

Chemicals and reagents. An anti- $\beta$-actin mouse monoclonal antibody (cat. no. A5441; 1:6,000), 4HR (cat. no. 209465), tartrate resistant acid phosphatase (TRAP) staining kit (cat. no. 387A) were purchased from Sigma-Aldrich; Merck KGaA. Rabbit polyclonal anti-TRAP (cat. no. 11594-1-AP; 1:1,000), Mouse monoclonal anti-nuclear factor of activated T-cells cytoplasmic 1 (NFATc1; cat. no. 66963-1-Ig; 1:1,000) and rabbit polyclonal anti-Cathepsin K (cat. no. 11239-1-AP; 1:1,000) antibodies were from ProteinTech Group, Inc. Rabbit monoclonal anti-phosphorylated $(\mathrm{p})$-I $\mathrm{\kappa B}$ kinase $\beta(\mathrm{pIKK} \beta$; cat. no. $2697 \mathrm{~S}, 1: 1,000)$ and total anti-IKK $\beta$ rabbit monoclonal (cat. no. 8943S; cat. no. 1:1,000) antibodies were obtained from Cell Signaling Technology, Inc. Recombinant soluble M-CSF and RANKL were obtained from PeproTech, Inc. Cell Counting Kit-8 (CCK-8) kit was purchased from Wuhan Boster Biological Technology, Ltd. Serum cross-linked procollagen type lamino-terminal propeptide (P1NP, cat. no. SEA570Mu) and C-terminal telopeptide of type1 collagen (CTX1, cat. no. CEA665Mu) ELISA kits were purchased from Cloud-Clone Corp.

In vitro osteoclastogenesis. The tibia and femur were dissected from 6-8-week-old male C57BL/6J mice (six mice were used; weight, $22.1 \pm 2.3 \mathrm{~g}$ ), mice were obtained from Experimental Animal Center of Tongji Medical College, then the mice were kept in animal center at $22^{\circ} \mathrm{C}$, humidity at $55 \%$, $12 \mathrm{~h}$ light/dark cycle with food and water ad libitum. After euthanasia, bone marrow-derived macrophages (BMMs) were flushed from tibia and femur of the mice. The cells were then centrifuged at $340 \mathrm{x}$ g for $5 \mathrm{~min}$ at room temperature and plated onto a 100-mm tissue culture dish containing $10 \%$ FBS (Gibco; Thermo Fisher Scientific, Inc.) and $10 \mathrm{ng} / \mathrm{ml}$ M-CSF. Because BMMs adhere slower than mesenchymal stem cells, the following day, non-adherent BMMs were collected according to a previous study by Zhao et al (24). The BMMs were cultured in $\alpha$-minimum essential medium ( $\alpha$-MEM;
Gibco; Thermo Fisher Scientific, Inc.) supplemented with $10 \%$ FBS and $10 \mathrm{ng} / \mathrm{ml} \mathrm{M-CSF}$. For osteoclastogenesis, BMMs were cultured at $37^{\circ} \mathrm{C}$ with $5 \% \mathrm{CO}_{2}$ in $\alpha$-MEM containing $10 \% \mathrm{FBS}$ in the presence of $10 \mathrm{ng} / \mathrm{ml} \mathrm{M-CSF}$ and $100 \mathrm{ng} / \mathrm{ml}$ RANKL for 5 days (25). BMMs at passage two were used. BMMs were treated with $0,5,10$ or $20 \mu \mathrm{g} / \mathrm{ml} 4 \mathrm{HR}$ for 5 days at $37^{\circ} \mathrm{C}$ with $5 \% \mathrm{CO}_{2}$ in the presence of $10 \mathrm{ng} / \mathrm{ml} \mathrm{M-CSF}$ and $100 \mathrm{ng} / \mathrm{ml}$ RANKL. TRAP staining was performed to visualize large mature OCs. The images were taken using a light microscope (Nikon Corporation) at x100 magnification. The number and area of mature OCs in each well were quantified using Image J $1.52 \mathrm{v}$ (National Institutes of Health). Briefly, the number of OCs was counted and the area of OCs was contoured and measured in each well, where the area was shown as \% osteoclastogenesis area/total area. For reverse transcription-quantitative PCR (RT-qPCR) and western blotting BMMs at passage two were treated with $20 \mu \mathrm{g} / \mathrm{ml} 4 \mathrm{HR}$ for 3 days or at different time points $(0,15,30,60 \mathrm{~min})$ at $37^{\circ} \mathrm{C}$ with $5 \% \mathrm{CO}_{2}$ in the presence of $10 \mathrm{ng} / \mathrm{ml} \mathrm{M-CSF}$ and $100 \mathrm{ng} / \mathrm{ml}$ RANKL.

$R T$ - $q P C R$. BMMs were cultured at $37^{\circ} \mathrm{C}$ in $\alpha$-MEM containing $10 \% \mathrm{FBS}$ in the presence of $10 \mathrm{ng} / \mathrm{ml} \mathrm{M}-\mathrm{CSF}$ and $100 \mathrm{ng} / \mathrm{ml} \mathrm{RANKL}$ for 3 days at $37^{\circ} \mathrm{C}$ and $5 \% \mathrm{CO}_{2}$ atmosphere, RNA was extracted using TRIzol (Invitrogen; Thermo Fisher Scientific, Inc.) (26). Total RNA was reverse transcribed into cDNA for RT-qPCR using the ReverAid First Strand cDNA Synthesis kit (Thermo Fisher Scientific, Inc.), briefly, the template RNA, primers, RiboLock RNase inhibitor and $10 \mathrm{mM}$ dNTP were mixed, incubated for $60 \mathrm{~min}$ at $42^{\circ} \mathrm{C}$ and terminated by heating at $70^{\circ} \mathrm{C}$ for $5 \mathrm{~min}$. qPCR was then performed using SsoAdvaced ${ }^{\mathrm{TM}}$ Universal SYBR Green Supermix (Bio-Rd Laboratories, Inc.) in CFX96 Real-time PCR Detection System (Bio-Rad Laboratories, Inc.). The thermocycling conditions were as follows: Initial denaturation at $95^{\circ} \mathrm{C}$ for $30 \mathrm{sec}$, followed by 40 cycles of $95^{\circ} \mathrm{C}$ for $5 \mathrm{sec}, 60^{\circ} \mathrm{C}$ for $30 \mathrm{sec}$ and $72^{\circ} \mathrm{C}$ for $30 \mathrm{sec}$. The primers were designed as follows: NFATc1 forward, 5'-TCTTCCGAG TTCACATCCC-3' and reverse, 5'-GACAGCACCATCTTC TTCC-3'; TRAP forward, 5'-CAGCAGCCAAGGAGGACT AC-3' and reverse, 5'-ACATAGCCCACACCGTTCTC-3' and Cathepsin $\mathrm{K}$ forward, 5'-CCAGTGGGAGCTATGGAA GA-3' and reverse, 5'-TGGTTCATGGCCAGTTCATA-3'. mRNA expression levels were normalized to those of mouse $\beta$-actin (forward, 5'-TGTTACCAACTGGGACGACA-3' and reverse, 5'-GGGGTGTTGAAGGTCTCAAA-3'). The relative mRNA levels of target genes were calculated using the $2^{-\Delta \Delta \mathrm{Cq}}$ method $(27,28)$.

Western blot analysis. BMMs were cultured at $37^{\circ} \mathrm{C}$ in $\alpha$-MEM containing $10 \% \mathrm{FBS}$ in the presence of $10 \mathrm{ng} / \mathrm{ml}$ M-CSF and $100 \mathrm{ng} / \mathrm{ml}$ RANKL for 5 days. Protein extracts were prepared in RIPA buffer (Wuhan Boster Biological Technology, Ltd.) at $4^{\circ} \mathrm{C}$ supplemented with $1 \%$ protease inhibitor and phosphatase inhibitors. Proteins were quantified using bicinchoninic acid protein assay (Wuhan Boster Biological Technology, Ltd.). In total, $10 \mu \mathrm{g}$ total protein per lane were separated using 10\% SDS-PAGE and then transferred onto PVDF membranes (EMD Millipore). Membranes were blocked with 5\% BSA (Wuhan Boster Biological 
Technology, Ltd.) in $0.1 \%$ TBS-Tween 20 for $60 \mathrm{~min}$ at room temperature and then incubated with the indicated primary antibodies overnight. The membranes were incubated with the appropriate horseradish peroxidase-conjugated secondary antibodies (1:10,000; cat. no. 31450 for anti-mouse, cat. no. 31460 for anti-rabbit; Thermo Fisher Scientific, Inc.) at room temperature for $2 \mathrm{~h}$. Finally, the membranes were visualized using Immun-Star HRP Chemiluminescent Substrate Kit (cat. no. 1705040; Bio-Rad Laboratories, Inc.) and the band densities were quantified using the Image Lab 5.1 software (Bio-Rad Laboratories, Inc.) and normalized to $\beta$-actin (29).

Luciferase assay. 293T cells (a gift from Dr Jun Xiao, Department of Orthopedics, Tongji Hospital, Huazhong University of Science and Technology; Wuhan, China) was cultured under a humidified $5 \% \mathrm{CO}_{2}$ atmosphere at $37^{\circ} \mathrm{C}$ in DMEM (Gibco; Thermo Fisher Scientific, Inc.) containing $10 \%$ FBS. In total, $1 \times 10^{4} 293 \mathrm{~T}$ cells were seeded onto each well in 96-well plate and were transfected with $200 \mathrm{ng}$ $\mathrm{NF}-\kappa \mathrm{B}$-luciferase reporter plasmid (pGL3), together with 50 ng phRG-TK Renilla-luciferase reporter plasmid (Promega Corporation) as a reference control, using Lipofectamine ${ }^{\circledR} 3000$ (Invitrogen; Thermo Fisher Scientific, Inc.). After 48 h, cells were incubated with or without $20 \mu \mathrm{g} / \mathrm{ml} 4 \mathrm{HR}$ for $30 \mathrm{~min}$. The luciferase activity measurement was performed according to the manufacturer's protocols (Dual-luciferase ${ }^{\circledR}$ reporter assay kit; Promega Corporation) (30), the luciferase signals were normalized to that of Renilla luciferase signals.

Animals and ovariectomy $(O V X)$. All animal experiments were approved by the Medical Ethics Committee of Tongji Medical College, Huazhong University of Science and Technology (Wuhan, China). The 4-month-old female $(28.3 \pm 1.8 \mathrm{~g})$ C57BL/6J mice used in the study were purchased from the Experimental Animal Center of Tongji Medical College. A total of 18 mice were used ( $n=6$ per group). All mice were housed under standard laboratory conditions at $22^{\circ} \mathrm{C}$, humidity at 55\%, 12-h light/dark cycle with ad libitum access to water and food.

For OVX and drug treatment, $1 \%$ isoflurane was used for anesthesia prior to surgery. The ovaries were bilaterally removed from all mice, except for those in the sham-operated group, where the ovaries were exposed but not removed, as previously described (31). Sham and one group of OVX mice received an equal volume of DMSO through an intraperitoneal injection daily for 60 days after surgery. The second OVX group received $1 \mathrm{mg} / \mathrm{kg} 4 \mathrm{HR}$ via an intraperitoneal injection daily for 60 days after surgery, which was designated as the OVX $+4 \mathrm{HR}$ group (32). The mice were anaesthetized in $1 \%$ isoflurane and then the serum was collected from $0.5 \mathrm{ml}$ blood before euthanasia. To obtain the serum, the blood samples were then centrifuged at $300 \mathrm{x} g$ at room temperature, then the supernatant was collected. All mice were sacrificed by cervical dislocation at 60 days after surgery following which the tibias were collected and scanned using microCT.

Bone specimen collection and microCT scanning. The tibias were dissected and fixed in $4 \%$ neutrally-buffered formalin for $48 \mathrm{~h}$. Following fixation, the tibias were scanned using vivaCT
40 (Scanco Medical AG) at a resolution of $15 \mu \mathrm{m}$ and $70 \mathrm{kVP}$, withan X-ray energy of $112 \mu \mathrm{A}$ (33). The parameters of bone volume per tissue volume (BV/TV), trabecular number (Tb.N), trabecular thickness (Tb.Th) and trabecular separation (Tb.Sp) were analyzed for each sample using SCANCO Medical's software 1.0 (Scanco Medical AG).

Histology. Following microCT scanning, the tibias were decalcified in $10 \%$ EDTA for 4 weeks at room temperature. Before sectioning, the tissues were embedded in paraffin. Sections were cut to a $5 \mu \mathrm{m}$ thickness, hydrated using xylene followed by a descending ethanol gradient and then stained with hematoxylin for $5 \mathrm{~min}$ at room temperature and eosin (H\&E) for $5 \mathrm{~min}$ at room temperature. TRAP staining was performed using a 387A kit (Merck KGaA), Briefly, a mixed solution of citrate solution, Fast Gamet GBC Base solution, naphthol AS-BI phosphonic acid solution and sodium nitrite solution were preheated at $37^{\circ} \mathrm{C}$ before tartrate solution was added to the mixture, the slides were then submerged into the mixed solution for $1 \mathrm{~h}$ at $37^{\circ} \mathrm{C}$ as previously described (34). All the pictures were taken under a light microscope at x200 magnification.

Analysis of serum biomarkers. Serum P1NP, an indicator of bone formation (35) and CTXI levels, an indicator of bone resorption (36), were measured using ELISA kits (Cloud-Clone Corp.) as previously described (37).

Statistical analysis. Data are presented as the mean \pm SD. For in vitro study, each experiment was repeated for $\geq$ three times, for in vivo study, each group contained six mice. For the cytotoxicity assays, RT-qPCR and western blotting analysis, data are presented as a percentage of the control or relative expression. For other experiments, real values are shown for each group. All data were analyzed using the SPSS 22 software (IBM Corp.). One-way ANOVAs followed by least significant difference (for three groups) or Tukey's post-hoc (for four groups) test were used to test the differences among the groups. Student's t-test was used to compare differences between two groups. $\mathrm{P}<0.05$ was considered to indicate a statistically significant difference.

\section{Results}

$4 H R$ reverses $R A N K L$-induced osteoclastogenesis. Osteoclastogenesis is a multistep process that is mediated by OC proliferation, commitment, fusion and activation triggered by RANKL (38) and the formation of giant multi-nucleated cells. To test the role of $4 \mathrm{HR}$ in osteoclastogenesis, BMMs were first isolated from the long bones of mice before cell viability was measured using CCK-8 assay. No significant difference could be observed when BMMs were exposed to different concentrations of $4 \mathrm{HR}(0$, 5, 10 and $20 \mu \mathrm{g} / \mathrm{ml}$; Fig. 1A), doses used was according to a study by Kim et al previously (21), indicating the lack of cytotoxicity by 4HR. To mimic osteoclastogenesis in vitro, BMMs were then treated with RANKL together with M-CSF to induce osteoclastogenesis, with or without the pretreatment with 4HR. 4HR significantly reduced the number of multinucleated TRAP-positive cells and TRAP-positive 
B

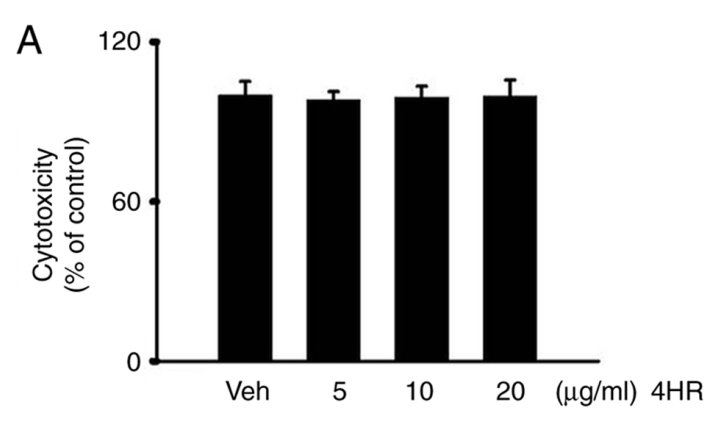

C

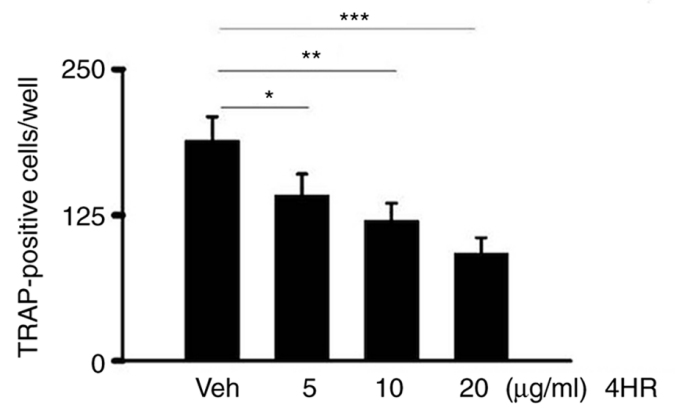

E

TRAP

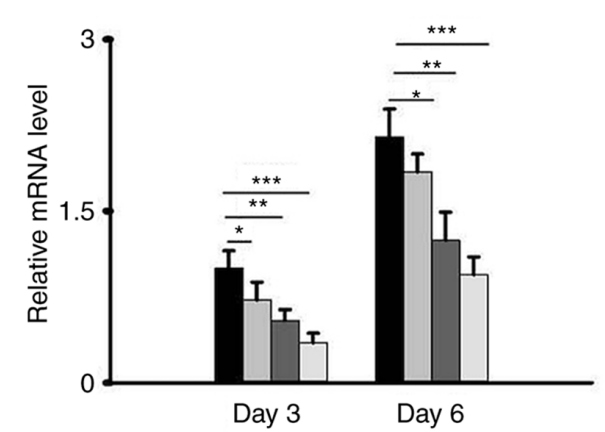

G

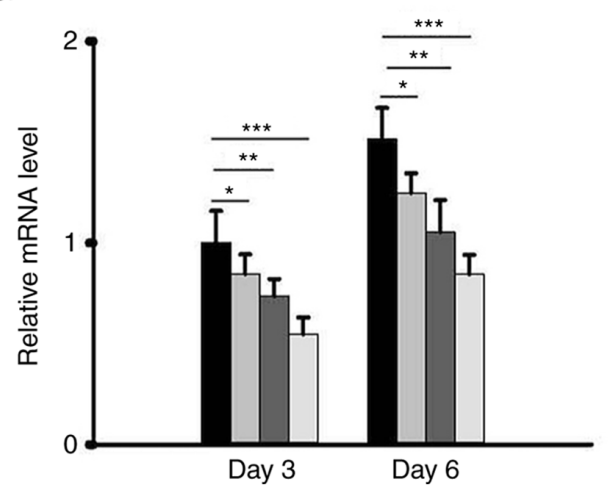

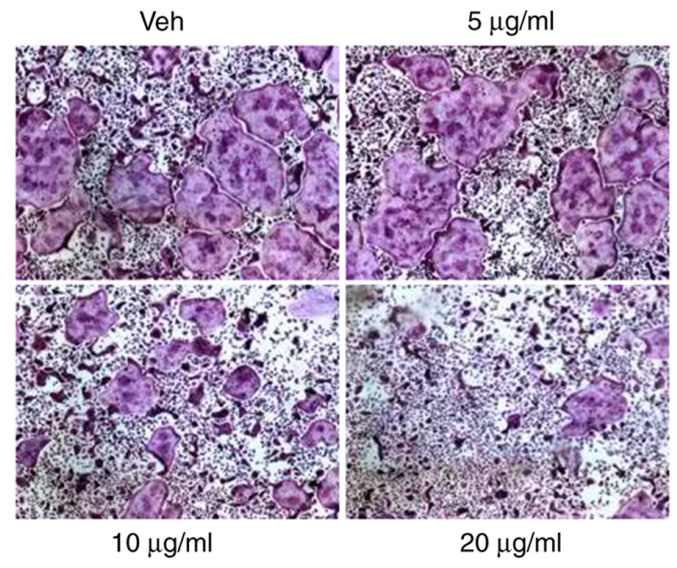

D

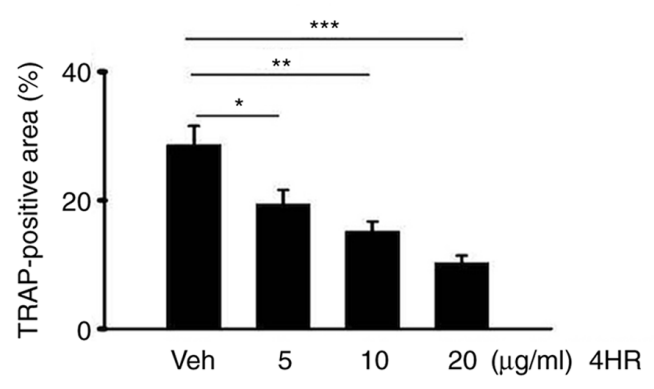

F

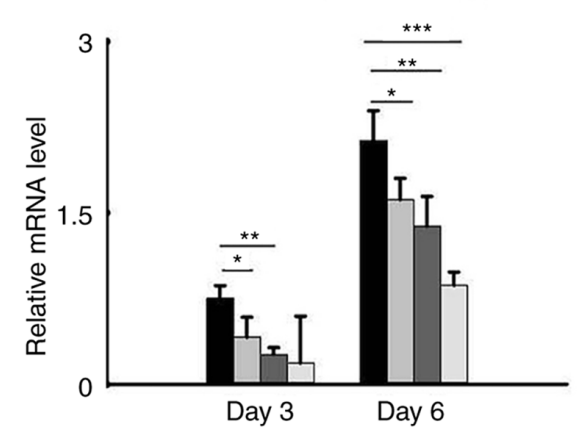

$\mathrm{H}$

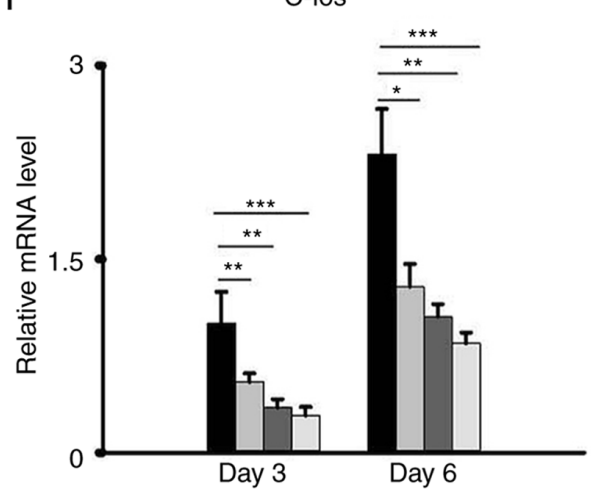

Figure 1. 4HR inhibits RANKL-induced osteoclastogenesis in vitro. (A-D) BMMs were seeded into 96-well plates and cultured at $37^{\circ} \mathrm{C}$ with complete medium supplemented with $10 \mathrm{ng} / \mathrm{ml}$ M-CSF and $100 \mathrm{ng} / \mathrm{ml}$ RANKL. (A) BMMs were treated with different concentrations of $4 \mathrm{HR}(0,5,10$ and $20 \mu \mathrm{g} / \mathrm{ml})$ for $3 \mathrm{days}$ in the presence of M-CSF. Cell viability was assessed using a Cell Counting Kit-8. No significant difference was observed among the groups. (B) Representative TRAP staining images on day 5 of OC differentiation following incubation with different concentrations of $4 \mathrm{HR}(0,5,10$ and $20 \mu \mathrm{g} / \mathrm{ml})$. Magnification, $\mathrm{x} 100$. (C) The number of TRAP-positive cells with $\geq$ three nuclei were quantified in each well in (B). ${ }^{*} \mathrm{P}<0.05,{ }^{* *} \mathrm{P}<0.01$ and ${ }^{* * * *} \mathrm{P}<0.001$. (D) The percentage of the TRAP-positive cell area in each well was measured in $(\mathrm{B}) .{ }^{*} \mathrm{P}<0.05,{ }^{* *} \mathrm{P}<0.01$ and ${ }^{* * *} \mathrm{P}<0.001$. (E-H) BMMs were treated with different concentrations of 4HR $(0,5,10$ and $20 \mu \mathrm{g} / \mathrm{ml})$ in the presence of $10 \mathrm{ng} / \mathrm{ml} \mathrm{M-CSF}$ and $100 \mathrm{ng} / \mathrm{ml}$ RANKL. mRNA expression levels of osteoclastogenesis markers (E) TRAP, (F) Cathepsin K, (G) NFATc1 and (H) c-Fos on day 3 of OC differentiation are shown for each group. ${ }^{*} \mathrm{P}<0.05$, ${ }^{* * *} \mathrm{P}<0.01$ and ${ }^{* * *} \mathrm{P}<0.001 .4 \mathrm{HR}, 4$-hexylresorcinol; RANKL, receptor activator of nuclear factor kappa B ligand; M-CSF, macrophage colony-stimulating factor; BMMs, bone marrow-derived macrophages; TRAP, tartrate resistant acid phosphatase; Veh, Vehicle; NFATc1, nuclear factor of activated T-cells c1. 
A

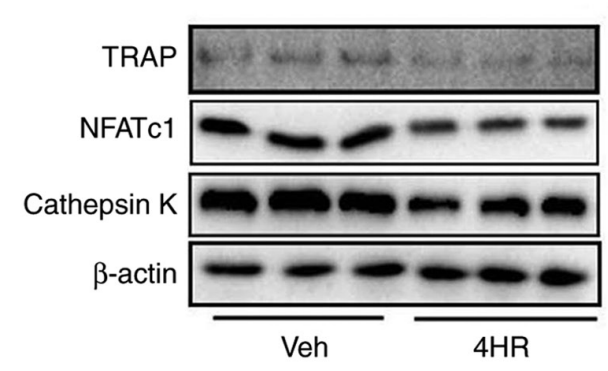

D

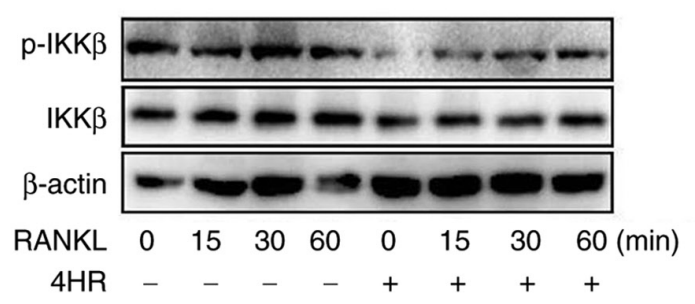

B

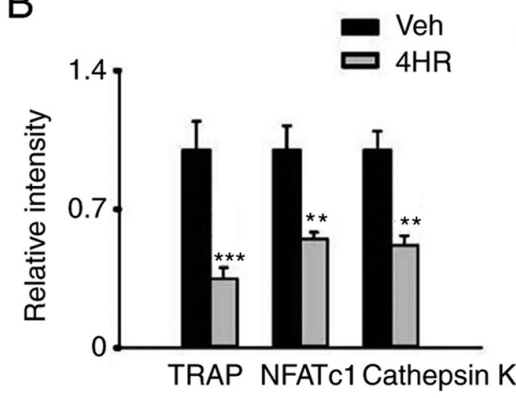

C

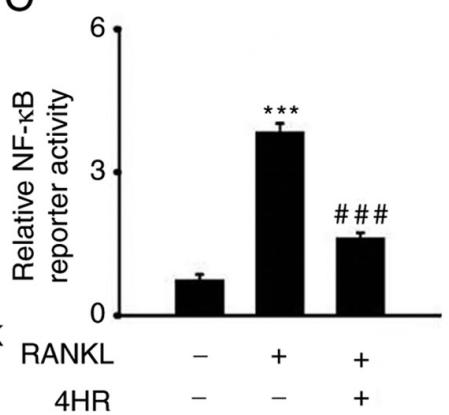

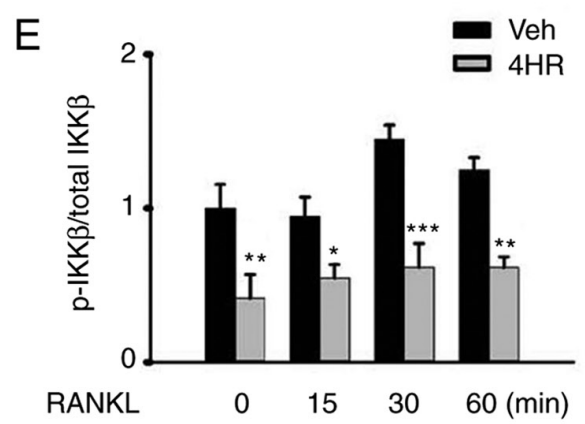

Figure 2. 4HR suppresses RANKL-induced activation of the NF- $\kappa$ B pathway. (A-E) BMMs cultured at $37^{\circ} \mathrm{C}$ with complete medium supplemented with $10 \mathrm{ng} / \mathrm{ml}$ M-CSF and $100 \mathrm{ng} / \mathrm{ml}$ RANKL. (A) Representative images of western blot analysis showing that 4HR inhibited the RANKL-induced protein expression of TRAP, NFATc1 and Cathepsin K in BMMs after $20 \mu \mathrm{g} / \mathrm{ml} 4 \mathrm{HR}$ treatment for 3 days in the presence of $10 \mathrm{ng} / \mathrm{ml} \mathrm{M}-\mathrm{CSF}$ and $100 \mathrm{ng} / \mathrm{ml} \mathrm{RANKL}$. (B) Quantification of (A). ${ }^{*} \mathrm{P}<0.05,{ }^{* *} \mathrm{P}<0.01,{ }^{* * *} \mathrm{P}<0.001$ vs. Veh. (C) Luciferase assay of the NF- $\mathrm{B}$ luciferase reporter plasmid in BMMs pretreated with or without $4 \mathrm{HR}(20 \mu \mathrm{g} / \mathrm{ml})$ for $30 \mathrm{~min}$ in the presence or absence of $10 \mathrm{ng} / \mathrm{ml} \mathrm{M}$-CSF and $100 \mathrm{ng} / \mathrm{ml} \mathrm{RANKL}$. ${ }^{* * *} \mathrm{P}<0.001 \mathrm{vs}$. Veh without $4 \mathrm{HR}$ treatment and RANKL stimulation, ${ }^{\# \# \# ~} \mathrm{P}<0.001$ vs. BMMs without $4 \mathrm{HR}$ treatment but with RANKL stimulation. (D) Western blot analysis of the lysate following 100 ng/ml RANKL incubation for the indicated time points $(0,15,30$ and $60 \mathrm{~min})$ in BMMs with or without $4 \mathrm{HR}$ preincubation for $30 \mathrm{~min}(20 \mu \mathrm{g} / \mathrm{ml})$ in the presence of $10 \mathrm{ng} / \mathrm{ml} \mathrm{M-CSF}$. (E) Quantification of (D). ${ }^{*} \mathrm{P}<0.05,{ }^{* *} \mathrm{P}<0.01$ and ${ }^{* * *} \mathrm{P}<0.001 \mathrm{vs}$. Veh without $4 \mathrm{HR}$ exposure at the corresponding time points. $4 \mathrm{HR}$, 4-hexylresorcinol; RANKL, receptor activator of NF- $\mathrm{B}$ ligand; TRAP, tartrate resistant acid phosphatase; NFATc1, nuclear factor of activated T-cells cytoplasmic 1; BMMs, bone marrow-derived macrophages; M-CSF, macrophage colony-stimulating factor; Veh, Vehicle; $\mathrm{p}$-IKK $\beta$, phosphorylated-IкB kinase $\beta$.

area in a dose-dependent manner $(0,5,10$ and $20 \mu \mathrm{g} / \mathrm{ml}$; Fig. 1B-D).The mRNA level of osteoclastogenesis-related genes, including TRAP, Cathepsin K, NFATc1 and c-fos, were significantly downregulated by preincubation with $4 \mathrm{HR}$ in a dose-dependent manner, suggesting an inhibitory effect of 4HR against osteogenesis (Fig. 1E-H).To further verify the effects of $4 \mathrm{HR}$ in osteoclastogenesis, the protein expression levels of those genes were also determined, where $20 \mu \mathrm{g} / \mathrm{ml}$ 4HR exposure significantly reduced the protein expression of TRAP, NFATc1 and Cathepsin Kin BMMs in the presence of RANKL (Fig. 2A and B).

4HR suppresses the RANKL-induced activation of the $N F-\kappa B$ pathway. $\mathrm{NF}-\kappa \mathrm{B}$ serves an important role in OC-induced osteoporosis and osteoclastogenesis $(39,40)$. To explore the molecular mechanism underlying $4 \mathrm{HR}$ in regulating the activity of the NF- $\kappa \mathrm{B}$ pathway, the effect of 4HR treatment on the NF- $\mathrm{BB}$ luciferase reporter was first examined in the 293T cell line. Following transfection, the cells were treated with RANKL, with or without 4HR preincubation, which resulted in a significant inhibition of $\mathrm{NF}-\kappa \mathrm{B}$ transactivation following preincubation with $20 \mu \mathrm{g} / \mathrm{ml} 4 \mathrm{HR}$ (Fig. 2C).

Subsequently, BMMs were further treated with M-CSF and RANKL in the presence of $20 \mu \mathrm{g} / \mathrm{ml} 4 \mathrm{HR}$ for $0,15,30$ and $60 \mathrm{~min}$, which lead to the phosphorylation of IKK $\beta$ being significantly reduced following pretreatment with $20 \mu \mathrm{g} / \mathrm{ml}$
4HR (Fig. 2D and E).These results suggest that 4HR treatment suppressed osteoclastogenesis by inhibiting the NF- $\kappa \mathrm{B}$ pathway.

4HR treatment reverses ovariectomy-induced bone loss in vivo. To test the role of $4 \mathrm{HR}$ in osteoporosis in vivo, an OVX model was constructed in female 4-month-old mice. MicroCT data showed that OVX significantly decreased bone mass in the proximal tibia, as evidenced by the significantly reduced BV/TV, Tb.N and Tb.Th values but significantly increased Tb.Sp values, in the OVX group compared with those in the sham group (Fig. 2). However, in mice that received $1 \mathrm{mg} / \mathrm{kg}$ 4HR administration, a marked reversal of OVX-induced bone loss was indicated by the significantly increased BV/TV, Tb.N and Tb.Th values but significantly decreased Tb.Sp values as compared with those in the OVX group. These results suggested a protective role for 4HR in osteoporosis in vivo (Fig. 3).

Bone mass was next examined using H\&E staining in paraffin-embedded bone slides. It was found that OVX reduced trabecular bone mass in the proximal tibia, since less trabecular bone was seen in the image. 4HR application, however, markedly rescued the bone loss, compared with that in OVX mice (Fig. 4A). To measure the OC number in vivo, TRAP staining was performed. OVX significantly increased the TRAP-positive cell number in the proximal tibia area, but 


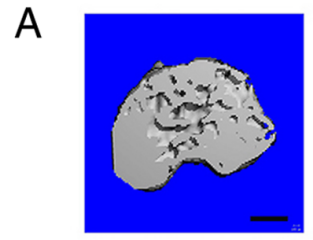

Sham

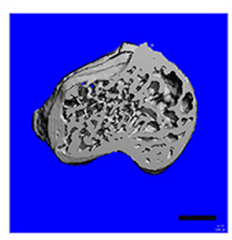

OVX

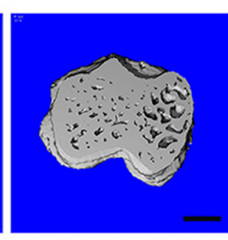

$\mathrm{OVX}+4 \mathrm{HR}$
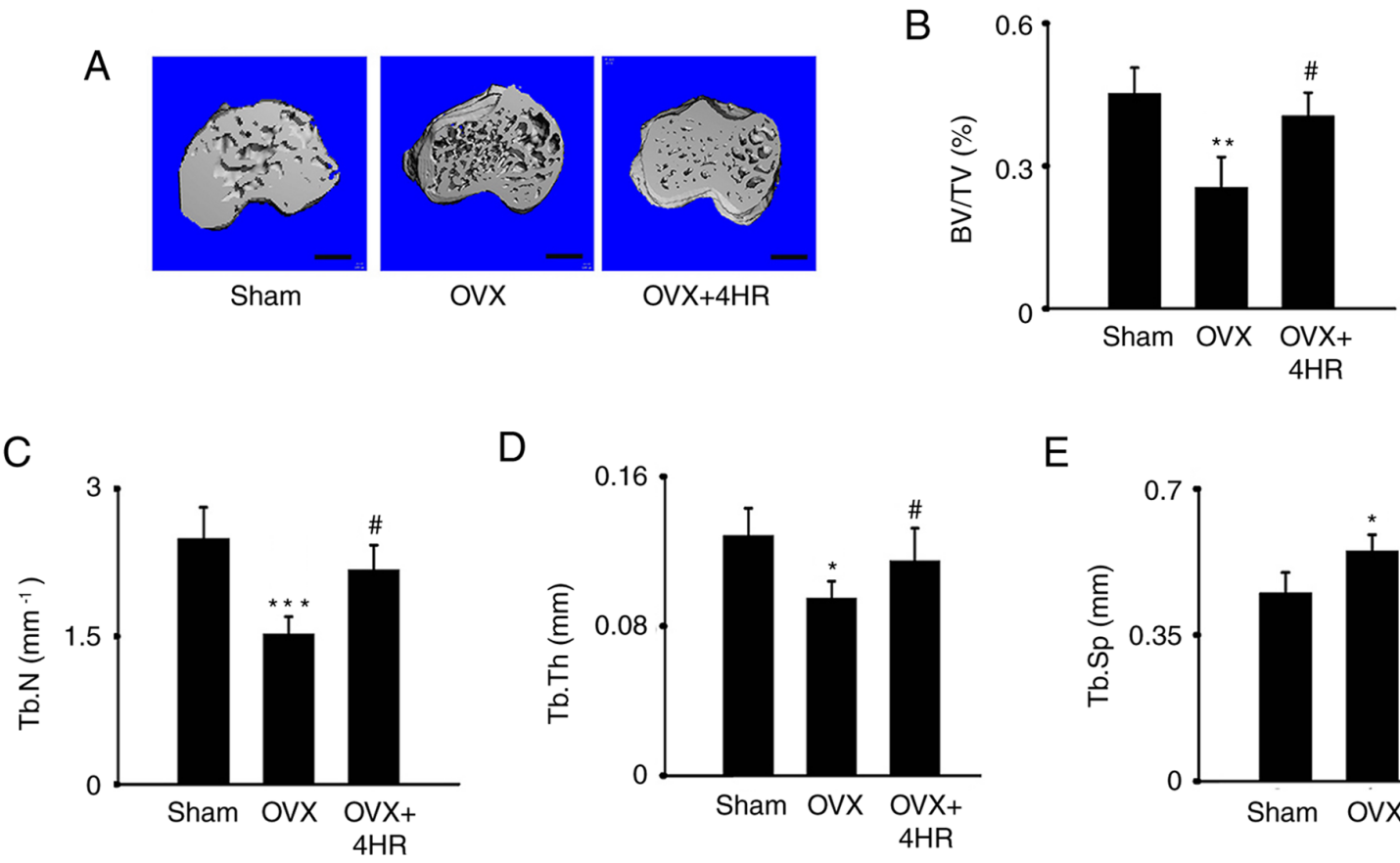

$\mathrm{D}$

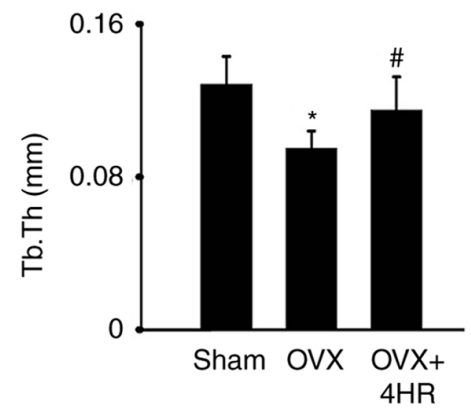

E

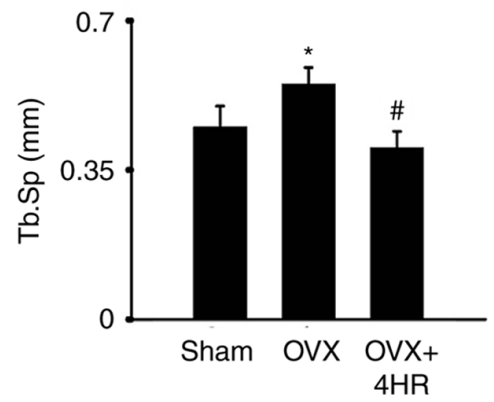

Figure 3.4HR treatment reverses ovariectomy-induced bone loss in vivo. (A) MicroCT images of the proximal tibia 60 days after ovariectomy surgery. Scale bar, $1 \mathrm{~mm}$. (B) BV/TV ratio was higher in the proximal tibia following 4HR administration for 60 days compared with that in the OVX group. (C) Quantification of Tb.N in the proximal tibia showed a significantly higher Tb.N in OVX mice treated with 4HR compared with those in OVX mice. (D) Quantification of Tb.Th showed a significantly higher Tb.Th following 4HR treatment for 60 days after OVX. (E) Quantification of Tb.Sp in 4HR treatment for 60 days after OVX. ${ }^{*} \mathrm{P}<0.05,{ }^{* *} \mathrm{P}<0.01$ and ${ }^{* * * *} \mathrm{P}<0.001$ vs. Sham. ${ }^{*} \mathrm{P}<0.05$ vs. OVX. $\mathrm{n}=6$ per group.4HR, 4-hexylresorcinol; BV/TV, bone volume/tissue volume; OVX, ovariectomy; Tb.N, trabecular number; Tb.Th, trabecular thickness; Tb.Sp, trabecular separation.

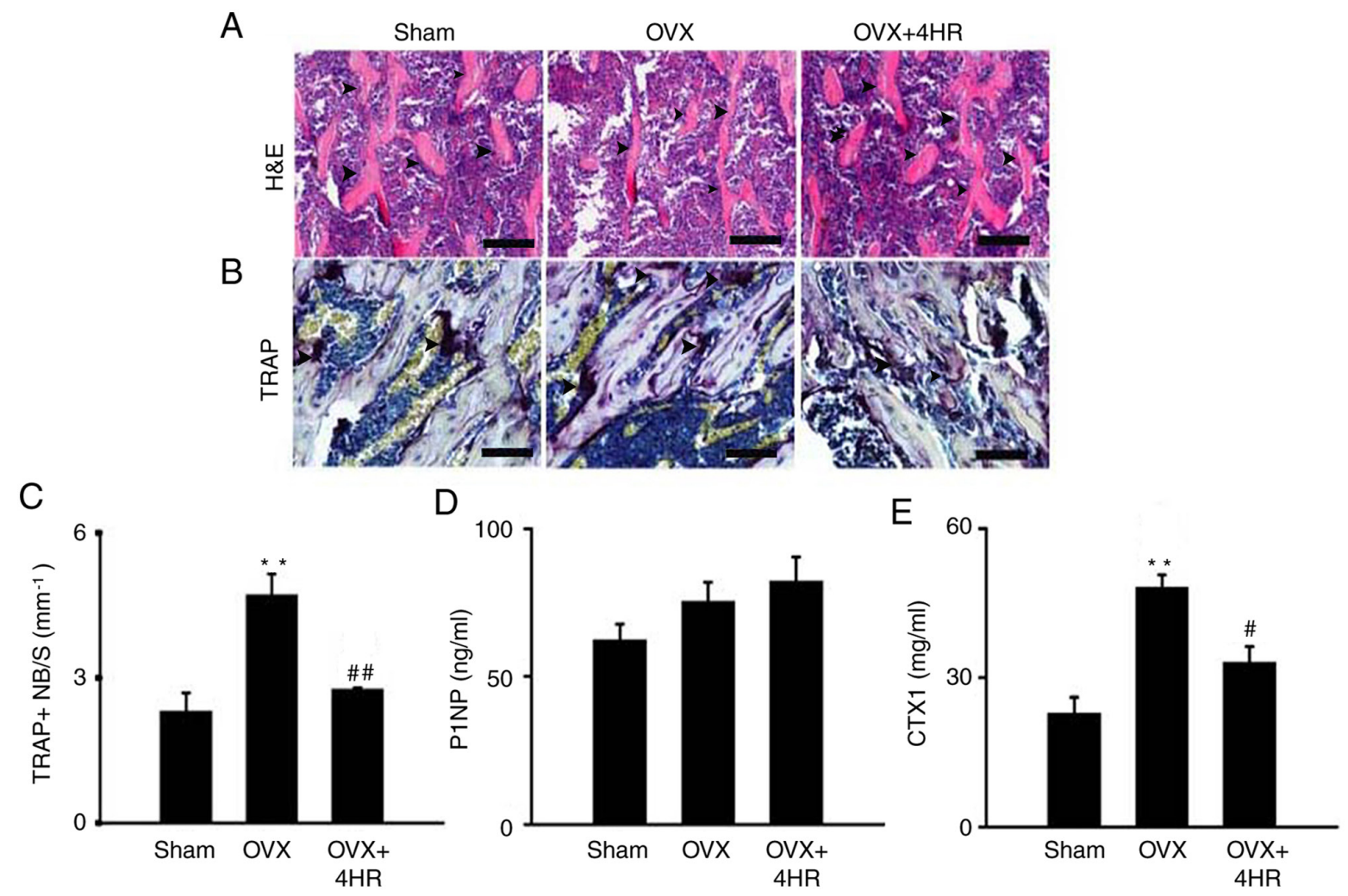

Figure 4. 4HR administration increases bone mass and reduces the OC number in vivo. (A) Representative images of H\&E staining of the proximal tibia following OVX with or without $4 \mathrm{HR}$ administration in mice, arrows showed the trabecular bones. Scale bar, $25 \mu \mathrm{m}$. (B) Representative images of TRAP staining in the proximal tibia in each group 60 days after OVX, arrows showed the purple multinucleated osteoclasts. Scale bar, $25 \mu$ m. (C) Quantification of TRAP positive cells in the proximal tibia 60 days after OVX. Data were shown as the OC number per bone surface/mm. Serum levels of (D) P1NP and (E) CTX1 were measured. ${ }^{* *} \mathrm{P}<0.01$ vs. Sham, ${ }^{\#} \mathrm{P}<0.05$ and ${ }^{\# \#} \mathrm{P}<0.01$ vs. OVX. $\mathrm{n}=6$ per group. 4HR, 4-hexylresorcinol; H\&E, hematoxylin and eosin; OVX, ovariectomy; TRAP, tartrate resistant acid phosphatase; P1NP, procollagen type 1 amino-terminal propeptide; CTX1, C-terminal telopeptide of type1; $\mathrm{NB} / \mathrm{S}$, number per bone surface. 
4HR treatment significantly reduced the TRAP-positive cell number compared with that in the OVX group (Fig. 4B and C), consistent with the in vitro and microCT data. Next, the levels of P1NP and CTX1, which are important bone formation and bone resorption markers, respectively $(41,42)$, were measured in the serum. OVX mice exhibited significantly higher CTX1 levels compared with those in the Sham mice, but there was no difference in the PTNP levels. However, 4HR treated mice exhibited a significantly lower level of CTX1 compared with that in the OVX mice, though no difference was observed in the P1NP levels (Fig. 4D and E). In conclusion, these data suggest that 4HR treatment ameliorates OVX-induced osteoporosis by inhibiting bone resorption without significantly affecting bone formation.

\section{Discussion}

Osteoclastogenesis is regulated by complex signaling cascades that are mainly triggered by RANKL (43). In the present study, 4HR application decreased RANKL-induced osteoclastogenesis in a dose-dependent manner in BMMs. In addition, 4HR significantly reduced TRAP-positive cell number and area. TRAP, cathepsin K, NFATc1 and c-fos are important osteoclastogenesis markers, since they enhance the differentiation and function of OCs (44). In the present study, BMMs treated with 4HR exhibited significantly lower TRAP, Cathepsin K, NFATc1 and C-fos expression levels. These findings were confirmed by both RT-qPCR and western blot analysis.

$\mathrm{OC}$ differentiation is regulated by multiple signaling pathways, one of the most important of which is the NF- $\mathrm{B}$ pathway in osteoclastogenesis (45). Activated $\mathrm{NF}-\kappa \mathrm{B}$ signaling pathway was found to be strongly associated with an increased OC activity, as evidenced by the increased $\mathrm{OC}$ number and activity in an ovariectomy model in mice (46). 4HR has been shown to downregulate the $\mathrm{NF}-\kappa \mathrm{B}$ pathway in human nasopharyngeal carcinoma cells (21). The present study showed that 4HR inhibits OC activity in osteoclastogenesis by suppressing $\mathrm{NF}-\kappa \mathrm{B}$, which may in turn exert its anti-osteoporosis function in vivo. It has also been reported previously that $\mathrm{NF}-\kappa \mathrm{B}$ contributes to OVX-induced bone loss (46). In the present study, using the $\mathrm{NF}-\kappa \mathrm{B}$ luciferase reporting plasmid, it was demonstrated that $4 \mathrm{HR}$ treatment induced $\mathrm{NF}-\kappa \mathrm{B}$ signaling suppression in the presence of RANKL in BMMs. Furthermore, phosphorylated IKK $\beta$ was reduced following 4 HR treatment. This suggests that $4 \mathrm{HR}$ inhibited osteoclastogenesis by suppressing the NF- $\kappa \mathrm{B}$ pathway.

OVX is a procedure that results in decreased estrogen that has been valuable for osteoporosis research (39). The main characteristic of this model is the increased OC number and activity (47). In the present study, administration of 4HR in mice resulted in a significantly reduced degree of bone loss induced by OVX as evidenced by microCT and histology data. The CT results also revealed elevated BV/TV, Tb.N and Tb.Th levels but lower Tb.Sp levels in the proximal tibia in $4 \mathrm{HR}$ treated mice. H\&E staining also showed decreased trabecular bone in the proximal tibia. To confirm whether the protective effect of 4HR was a result of osteoclastogenesis inhibition, TRAP staining was performed to quantify the TRAP-positive cell number in each group. The results showed that the number of TRAP-positive cells was increased in OVX mice compared with that in Sham mice. By contrast, 4HR administration markedly decreased the number of TRAP-positive cells compared with that in OVX mice.

Since estrogen deficiency is one of the main causes of menopausal osteoporosis (48), it would be interesting to explore whether the mechanism of $4 \mathrm{HR}$ action is also associated with estrogen levels in vivo, including increased estrogen receptor activity. However, since there is currently no evidence of a direct connection, future studies should investigate this potential relationship (47).The present study on osteoclastogenesis were consistent with those reported by Choi et al (23), which showed that 4HR improved OB function in ovariectomized rats, confirming the potential use of 4HR for the treatment of osteoporosis. A limitation of the present study was that it remains unclear if OBs also participated in the role of $4 \mathrm{HR}$ in this OVX model. It is well-established that the maintenance of normal bone mass is dependent on the balance between $\mathrm{OB}$ and $\mathrm{OC}$ activity. No difference in the level of bone formation marker P1NP was identified among the three mouse groups, suggesting that 4HR may not have had an effect on OB activity in the present model. Therefore, future studies should extend this investigation to OBs.

In conclusion, the present study found that $4 \mathrm{HR}$ exerted a protective effect against osteoporosis by reducing osteoclastogenesis both in vitro and in vivo. This may provide a novel insight into the clinical study of osteoporosis and encourage the further exploration of reagents for the treatment of osteoporosis.

\section{Acknowledgements}

The authors would like to thank Dr Jun Xiao (Department of Orthopedics, Tongji Hospital, Huazhong University of Science and Technology; Wuhan, China) for the kind gift of $293 \mathrm{~T}$ cells used in the present study.

\section{Funding}

The present study was supported by the Medical Research Foundation of Wuhan City (grant no. WZ19A05) and the Hygiene and Health Joint Foundation of Hubei Province (grant no. WJ2019H412).

\section{Availability of data and materials}

The datasets used and/or analyzed during the present study are available from the corresponding author upon reasonable request.

\section{Authors' contributions}

ML designed the experiments. WY performed western blotting, reverse transcription-quantitative PCR, collected samples, microCT scanning, $\mathrm{HE}$ and TRAP staining. TL contributed to the $N F-\kappa B$ reporter assay. $X G$ and $Y X$ performed the OVX surgery. WY and ML authenticate the raw data. All authors read and approved the final version of the manuscript. 


\section{Ethics approval and consent to participate}

All animal experiments were approved by the Medical Ethics Committee of Tongji Medical College, Huazhong University of Science and Technology (Wuhan, China).

\section{Patient consent for publication}

Not applicable.

\section{Competing interests}

The authors declare that they have no competing interests.

\section{References}

1. Kanis JA: Assessment of fracture risk and its application to screening for postmenopausal osteoporosis: Synopsis of a WHO report. WHO study group. Osteoporos Int 4: 368-381, 1994.

2. Hernlund $\mathrm{E}$, Svedbom A, Ivergård $\mathrm{M}$, Compston $\mathrm{J}$, Cooper $\mathrm{C}$, Stenmark J, McCloskey EV, Jönsson B and Kanis JA: Osteoporosis in the European union: Medical management, epidemiology and economic burden. A report prepared in collaboration with the international osteoporosis foundation (IOF) and the European federation of pharmaceutical industry associations (EFPIA). Arch Osteoporos 8: 136, 2013.

3. Tom SE, Adachi JD, Anderson FA Jr, Boonen S, Chapurlat RD, Compston JE, Cooper C, Gehlbach SH, Greenspan SL, Hooven FH, et al: Frailty and fracture, disability, and falls: A multiple country study from the global longitudinal study of osteoporosis in women. J Am Geriatr Soc 61: 327-334, 2013.

4. Johnell O and Kanis J: Epidemiology of osteoporotic fractures. Osteoporos Int 16 (Suppl 2): S3-S7, 2005.

5. Eriksen EF: Cellular mechanisms of bone remodeling. Rev Endocr Metab Disord 11: 219-227, 2010.

6. Chen X, Wang Z, Duan N, Zhu G, Schwarz EM and Xie C: Osteoblast-osteoclast interactions. Connect Tissue Res 59: 99-107, 2018

7. Kikuta J and Ishii M: Bone imaging: Osteoclast and osteoblast dynamics. Methods Mol Biol 1763: 1-9, 2018.

8. Roodman GD: Cell biology of the osteoclast. Exp Hematol 27: 1229-1241, 1999

9. Datta HK, Ng WF, Walker JA, Tuck SP and Varanasi SS: The cell biology of bone metabolism. J Clin Pathol 61: 577-587, 2008.

10. Zaidi M: Skeletal remodeling in health and disease. Nat Med 13 791-801, 2007.

11. Trouvin AP and Goëb V: Receptor activator of nuclear factor- $\kappa \mathrm{B}$ ligand and osteoprotegerin: Maintaining the balance to prevent bone loss. Clin Interv Aging 5: 345-354, 2010.

12. Boyce BF and Xing L: Functions of RANKL/RANK/OPG in bone modeling and remodeling. Arch Biochem Biophys 473: 139-146, 2008

13. Lewiecki EM: Denosumab: A promising drug for the prevention and treatment of osteoporosis. Womens Health (Lond) 2 $517-525,2006$

14. Eastell R, Christiansen C, Grauer A, Kutilek S, Libanati C, McClung MR, Reid IR, Resch H, Siris E, Uebelhart D, et al: Effects of denosumab on bone turnover markers in postmenopausal osteoporosis. J Bone Miner Res 26: 530-537, 2011.

15. Kendler DL, Roux C, Benhamou CL, Brown JP, Lillestol M, Siddhanti S, Man HS, San Martin J and Bone HG: Effects of denosumab on bone mineral density and bone turnover in postmenopausal women transitioning from alendronate therapy. J Bone Miner Res 25: 72-81, 2010.

16. Gupta G and Aronow WS: Treatment of postmenopausal osteoporosis. Compr Ther 33: 114-119, 2007.

17. Lewiecki EM: Denosumab in postmenopausal osteoporosis: What the clinician needs to know. Ther Adv Musculoskele Dis 1: 13-26, 2009.

18. Silva I and Branco JC: Denosumab: Recent update in postmenopausal osteoporosis. Acta Reumatol Port 37: 302-313, 2012.

19. Kim MK, Yoon CS, Kim SG, Park YW, Lee SS and Lee SK: Effects of 4-hexylresorcinol on protein expressions in RAW 264.7 cells as determined by immunoprecipitation high performance liquid chromatography. Sci Rep 9: 3379, 2019.
20. Rabbani GH, Gilman RH, Kabir I and Mondel G: The treatment of fasciolopsis buski infection in children: A comparison of thiabendazole, mebendazole, levamisole, pyrantel pamoate, hexylresorcinol and tetrachloroethylene. Trans R Soc Trop Med Hyg 79: 513-515, 1985.

21. Kim SG, Lee SW, Park YW, Jeong JH and Choi JY: 4-hexylresorcinol inhibits NF- $\kappa$ B phosphorylation and has a synergistic effect with cisplatin in KB cells. Oncol Rep 26: 1527-1532, 2011.

22. He J,Zhu Q, Dong X, Pan H, Chen J and Zheng ZP: Oxyresveratrol and ascorbic acid O/W microemulsion: Preparation, characterization, anti-isomerization and potential application as antibrowning agent on fresh-cut lotus root slices. Food Chem 214: 269-276, 2017.

23. Choi KH, Kim DW, Lee SK, Kim SG and Kim TW: The administration of 4-hexylresorcinol accelerates orthodontic tooth movement and increases the expression level of bone turnover markers in ovariectomized rats. Int J Mol Sci 21: 1526, 2020.

24. Zhao L, Guan H, Song C, Wang Y, Liu C, Cai C, Zhu H, Liu H, Zhao L and Xiao J: YAP1 is essential for osteoclastogenesis through a TEADs-dependent mechanism. Bone 110: 177-186, 2018.

25. Bae S, Lee MJ, Mun SH, Giannopoulou EG, Yong-Gonzalez V, Cross JR, Murata K, Giguère V, van der Meulen $M$ and Park-Min KH: MYC-dependent oxidative metabolism regulates osteoclastogenesis via nuclear receptor ERR $\alpha$. J Clin Invest 127: 2555-2568, 2017.

26. Chomczynski P and Sacchi N: Single-step method of RNA isolation by acid guanidinium thiocyanate-phenol-chloroform extraction. Anal Biochem 162: 156-159, 1987.

27. Livak KJ and Schmittgen TD: Analysis of relative gene expression data using real-time quantitative PCR and the 2(-Delta Delta C(T)) method, Methods 25: 402-408, 2001.

28. Sun X, Gao X, Deng Z, Zhang L, McGilvray K, Gadomski BC, Amra S, Bao G and Huard J: High bone microarchitecture, strength, and resistance to bone loss in MRL/MpJ mice correlates with activation of different signaling pathways and systemic factors. FASEB J 34: 789-806, 2020.

29. Farahzadi R, Fathi E and Vietor I: Mesenchymal stem cells could be considered as a candidate for further studies in cell-based therapy of alzheimer's disease via targeting the signaling pathways. ACS Chem Neurosci 11: 1424-1435, 2020.

30. Deng Y, Lu J, Li W, Wu A, Zhang X, Tong W, Ho KK, Qin L, Song $\mathrm{H}$ and Mak KK: Reciprocal inhibition of YAP/TAZ and $\mathrm{NF}-\kappa \mathrm{B}$ regulates osteoarthritic cartilage degradation. Nat Commun 9: 4564, 2018.

31. Idris AI: Ovariectomy/orchidectomy in rodents. Methods Mol Biol 816: 545-551, 2012.

32. Huo J and Sun X: Effect of astragalus polysaccharides on ovariectomy-induced osteoporosis in mice. Genet Mol Res 15, 2016.

33. Gao X, Usas A, Tang Y, Lu A, Tan J, Schneppendahl J, Kozemchak AM, Wang B, Cummins JH, Tuan RS and Huard J: A comparison of bone regeneration with human mesenchymal stem cells and muscle-derived stem cells and the critical role of BMP. Biomaterials 35: 6859-6870, 2014.

34. Lee Y, Kim HJ, Park CK, Kim YG, Lee HJ, Kim JY and Kim HH: MicroRNA-124 regulates osteoclast differentiation. Bone 56: 383-389, 2013.

35. Takada J, Dinavahi R, Miyauchi A, Hamaya E, Hirama T, Libanati C, Nakamura Y, Milmont CE and Grauer A: Relationship between P1NP, a biochemical marker of bone turnover, and bone mineral density in patients transitioned from alendronate to romosozumab or teriparatide: A post hoc analysis of the STRUCTURE trial. J Bone Miner Metab 38: 310-315, 2020.

36. Xu S, Zhang Y, Wang J, Li K, Tan K, Liang K, Shen J, Cai D, Jin D, Li M, et al: TSC1 regulates osteoclast podosome organization and bone resorption through mTORC1 and Rac1/Cdc42. Cell Death Differ 25: 1549-1566, 2018.

37. Zhang Y, Xu S, Li K, Tan K, Liang K, Wang J, Shen J, Zou W, $\mathrm{Hu} \mathrm{L}$, Cai D, et al: mTORC1 inhibits NF- $\mathrm{KB} / \mathrm{NFATc1}$ signaling and prevents osteoclast precursor differentiation, in vitro and in mice. J Bone Miner Res 32: 1829-1840, 2017.

38. Lorenzo J, Horowitz M and Choi Y: Osteoimmunology: Interactions of the bone and immune system. Endocr Rev 29: 403-440, 2008.

39. Lin TH, Pajarinen J, Lu L, Nabeshima A, Cordova LA, Yao Z and Goodman SB: NF- $\kappa$ B as a therapeutic target in inflammatory-associated bone diseases. Adv Protein Chem Struct Biol 107: 117-154, 2017

40. Abu-Amer Y: NF- $\mathrm{BB}$ signaling and bone resorption. Osteoporos Int 24: 2377-2386, 2013. 
41. Liu TT, Liu DM, Xuan Y, Zhao L, Sun LH, Zhao DD, Wang XF, He Y, Guo XZ, Du R, et al: The association between the baseline bone resorption marker CTX and incident dysglycemia after 4 years. Bone Res 5: 17020, 2017.

42. Thurairaja R, Iles RK, Jefferson K, McFarlane JP and Persad RA: Serum amino-terminal propeptide of type 1 procollagen (P1NP) in prostate cancer: A potential predictor of bone metastases and prognosticator for disease progression and survival. Urol Int 76: 67-71, 2006.

43. Boyle WJ, Simonet WS and Lacey DL: Osteoclast differentiation and activation. Nature 423: 337-342, 2003.

44. Boyce BF, Xiu Y, Li J, Xing L and Yao Z: NF-кB-mediated regulation of osteoclastogenesis. Endocrinol Metab (Seoul) 30: 35-44, 2015.

45. Silva I and Branco JC: Rank/Rankl/opg: Literature review. Acta Reumatol Port 36: 209-218, 2011.

46. Onal M, Xiong J, Chen X, Thostenson JD, Almeida M, Manolagas SC and O'Brien CA: Receptor activator of nuclear factor $\kappa \mathrm{B}$ ligand (RANKL) protein expression by $\mathrm{B}$ lymphocytes contributes to ovariectomy-induced bone loss. J Biol Chem 287 29851-29860, 2012.
47. Salamanna F, Borsari V, Contartese D, Nicoli Aldini N and Fini M: Link between estrogen deficiency osteoporosis and susceptibility to bone metastases: A way towards precision medicine in cancer patients. Breast 41: 42-50, 2018.

48. Kanis JA, Cooper C, Rizzoli R and Reginster JY; Scientific Advisory Board of the European Society for Clinical and Economic Aspects of Osteoporosis (ESCEO) and the Committees of Scientific Advisors and National Societies of the International Osteoporosis Foundation (IOF): European guidance for the diagnosis and management of osteoporosis in postmenopausal women. Osteoporos Int 30: 3-44, 2019.

This work is licensed under a Creative Commons Attribution-NonCommercial-NoDerivatives 4.0 International (CC BY-NC-ND 4.0) License. 